\title{
High-Pressure Injection Injuries to the Hand
}

\author{
Davod Jafari, ${ }^{1}$ Tahmineh Mokhtari, ${ }^{2}$ Hooman Shariatzadeh, ${ }^{1}$ and Toraj Kamali ${ }^{1,}$ \\ ${ }^{1}$ Bone and Joint Reconstruction Research Center, Shafa Orthopedic Hospital, Iran University of Medical Sciences, Tehran, IR Iran \\ ${ }^{2}$ School of Medicine, Tehran University of Medical Sciences, Tehran, IR Iran \\ "Corresponding author: Toraj Kamali, Bone and Joint Reconstruction Research Center, Shafa Orthopedic Hospital, Iran University of Medical Sciences, Tehran, IR Iran. Tel: \\ +98-21335420210, Fax: +98-2133542020, E-mail: torajkamaly@yahoo.com
}

Received 2015 September 22; Revised 2016 April 24; Accepted 2016 July 08.

\begin{abstract}
Background: High-pressure injections into the hand, burden devastating and permanent functional impairments. Many materials including paint, paint thinner, gasoline, oil and grease are reported as the causative agents. These injuries need multiple procedures and reconstructions most of the time and $40 \%$ of the injuries may end with amputation of the injured part.

Objectives: The aim of this study was to report the treatment outcomes and methods of treatments of patients with high-pressure injection injuries of the hand.

Methods: We retrospectively reviewed the medical records, imaging files and demographic data of patients, who were treated at our center due to the high-pressure injuries to their hands. We recorded the kind of the injected materials, time to the first treatment procedure, times of operation, and methods of their treatments. The outcomes of the injuries as well as the deficiency of the digital joints motion were also reported.

Results: Nine cases with high-pressure injury of the hand were enrolled in this study. All patients were male with mean age of 26.88 \pm 7.52. Mean follow-up time was $28.55 \pm 12.49$ months. The dominant hand was the right side in seven patients and left in two patients. Injury was in the left hand of seven patients and right hand of two patients. Index finger was the most common involved part (five cases) followed by the thumb (two cases). Injected material was grease in seven cases, water-base paint and water, each in one case.Mean time delay to the first treatment procedure was $29.16 \pm 25.66$ hours for seven patients. This was exceptionally long for two patients (seven days and 24 months). Type of treatment was debridement and skin graft for three cases, debridement and cross finger flap for two cases, debridement for two cases and nerve graft for one case. Amputation of the necrotic digit was performed for one case. Mean hospitalization time was $8.33 \pm 3.64$ days for all patients.Mean total active range of motion (TAROM) deficit was 18.57 \pm 13.13 degrees for seven cases. In one case, mean deficit of II to IV fingers was 170. Seven cases returned to their previous occupation. There was no correlation between time to first treatment procedure and TAROM deficit.

Conclusions: These benign-looking injuries should not be underestimated and classic management including immediate surgical decompression is recommended to minimize the functional impairments.
\end{abstract}

Keywords: Hand, High Pressure, Injection Injury, Outcome

\section{Background}

High-pressure injections in the hand can result in devastating injuries with permanent functional impairments. They usually need multiple procedures and reconstructions to overcome tissue necrosis and infection. These injuries can end to soft tissue contractures, loss of strength, sensation, and function or even amputation (1).

Wide varieties of materials have been reported in the literature as offensive agents such as water, paint, paint thinner, gasoline, oil and grease. The organic material can result in amputation in more than $40 \%$ of the injuries $(1,2)$.

Fingers are the most common location for highpressure injection injuries. The symptoms are mild and the pain is minimal most of the time. The entrance of the substance is a small innocent looking wound. The minimal symptoms and benign-looking injury frequently leads to delay in seeking medical assistance, which in turn results in more intense and severe disabilities (1).

Management of these injuries is based on the severity of the injury, the nature of the injected material and the burdened consequences after the injection. Immediate and aggressive surgical decompression followed by injected materials removal results in significant loss of the soft and vital tissues of the hand, which demands delicate reconstruction procedures in the next steps (3).

\section{Objectives}

The aim of the present study was to review the treatment outcomes of our patients with high-pressure injection injuries of the hand as well as the demographic data, 
the nature of the injected material, time to the first treatment procedure, times of operation and kind of treatment.

\section{Methods}

The study was approved by ethic board of our institution. We conducted a retrospective review study of all patients admitted to our hospital due to high-pressure injection injuries to the hand. Nine patients were identified with this kind of injury from June 2010 to April 2014. We reviewed the medical records, imaging files and demographic data including gender, age, hand dominancy, and site of the injury and injured finger. The kind of injected materials, time to the first treatment procedure, times of operation, kind of treatment as well as the days of hospitalization were recorded. The patients were recalled for the final assessment of the treatment outcomes by physical examination, range of motion deficiency of the nearby joints.

The treatment approach for all patients was tetanus prophylaxis and broad-spectrum antibiotics and immediate surgical treatment under general anesthesia; we used Bruner zig-zag incision to decompress the affected part of the hand using a tourniquet. In most cases the entrance of the injected materials was a small point surrounded by swelling and inflammation (Figure 1). We used radiographs to estimate the extent of soft tissue involvement in cases with radiopaque materials (Figure 2A) but intra operative findings were the most accurate assessment (Figure 2B). Meticulous debridement of all devitalized tissue and irrigation with large amounts of saline without using any chemical solvent were done for our patients (Figure 2C). Repeated debridement was performed to reach an infection-free highly vascular tissue, and we then decided to do soft tissue reconstruction as indicated by the wound condition (Figure 3). Delayed closure, full thickness skin graft and cross finger flap were used as these technique (Figure 4). Prolonged and intensive physiotherapy was advocated to improve the small joints range of motion and to minimize the sequels of this devastating injury. Data were analyzed by the SPSS-16 software (SPSS Inc, Chicago, Illinois, the United States). Descriptive statistics was used to present the data. Mean \pm standard deviation (SD) was used for quantitative data. Frequency was used for qualitative data. The correlation between two quantitative data was evaluated. P values of $\leq 0.05$ were considered significant.

\section{Results}

In this study, nine cases with high-pressure injury of the hand were evaluated. According to Table 1, mean age

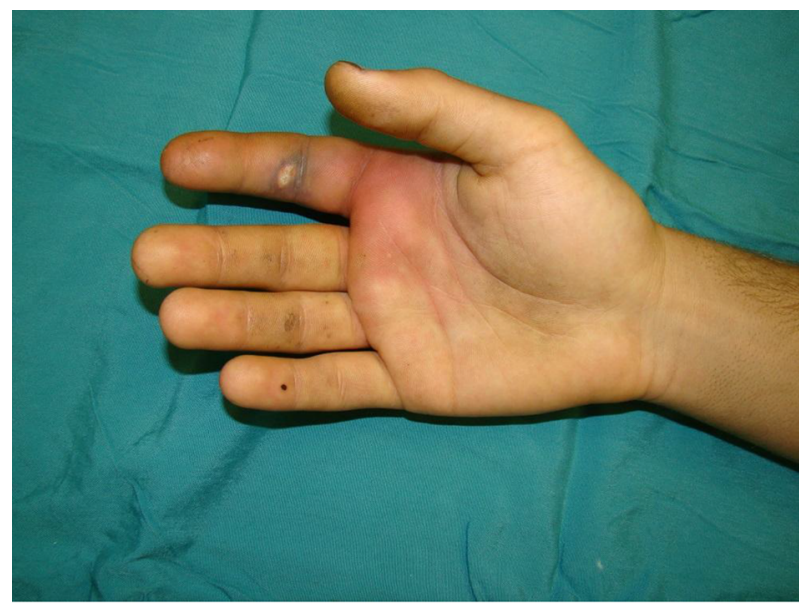

Figure 1. The Entrance of the Injected Materials; A Small Point Surrounded by Swelling and Inflammation (Case No.1)

was $26.88 \pm 7.52$ and all patients were male. The occupation of six patients $(66.66 \%)$ was mechanic. The dominant hand was the right hand in seven patients (77.77\%) and left hand in two patients (22.22\%). Injury was in the left hand of seven patients (77.77\%) and right hand of two patients (22.22\%). The involved area was the index volar in five cases (55.55\%), thumb volar in two cases (22.22\%), palm thenar in one case $(11.11 \%$ ) and palm in one case $(11.11 \%)$. Injected material was grease in seven cases (77.77\%), water-base paint in one case (11.11\%) and water in one case (11.11\%).

According to Table 2, mean time to first treatment procedure was $29.16 \pm 25.66$ hours for seven patients. This time was exceptionally long for two patients (seven days and 24 months for cases number eight and five, respectively). Type of treatment was debridement and skin graft for three cases (four operations for two cases and five operations for the other one), debridement and cross finger flap for two cases (six and five operations, respectively), debridement for two cases (three operations for each case) and nerve graft for one case (once). Also, amputation of the necrotic digit was performed for one case. Mean hospitalization time was $8.33 \pm 3.64$ days for all patients.

Mean total active range of motion (TAROM) deficit was $18.57 \pm 13.13$ degrees for seven cases. In one case, (No. 6) mean deficit of II to IV fingers was 170 and in one case (No. 8) the digit was amputated. Seven cases (77.77\%) returned to their previous occupation. Mean follow-up time was 28.55 \pm 12.49 months. There was no correlation between time to first treatment procedure and TAROM deficit $(\mathrm{P}=0.723, \mathrm{r}=$ $-0.163)$. This was partly due to the small number of cases. 

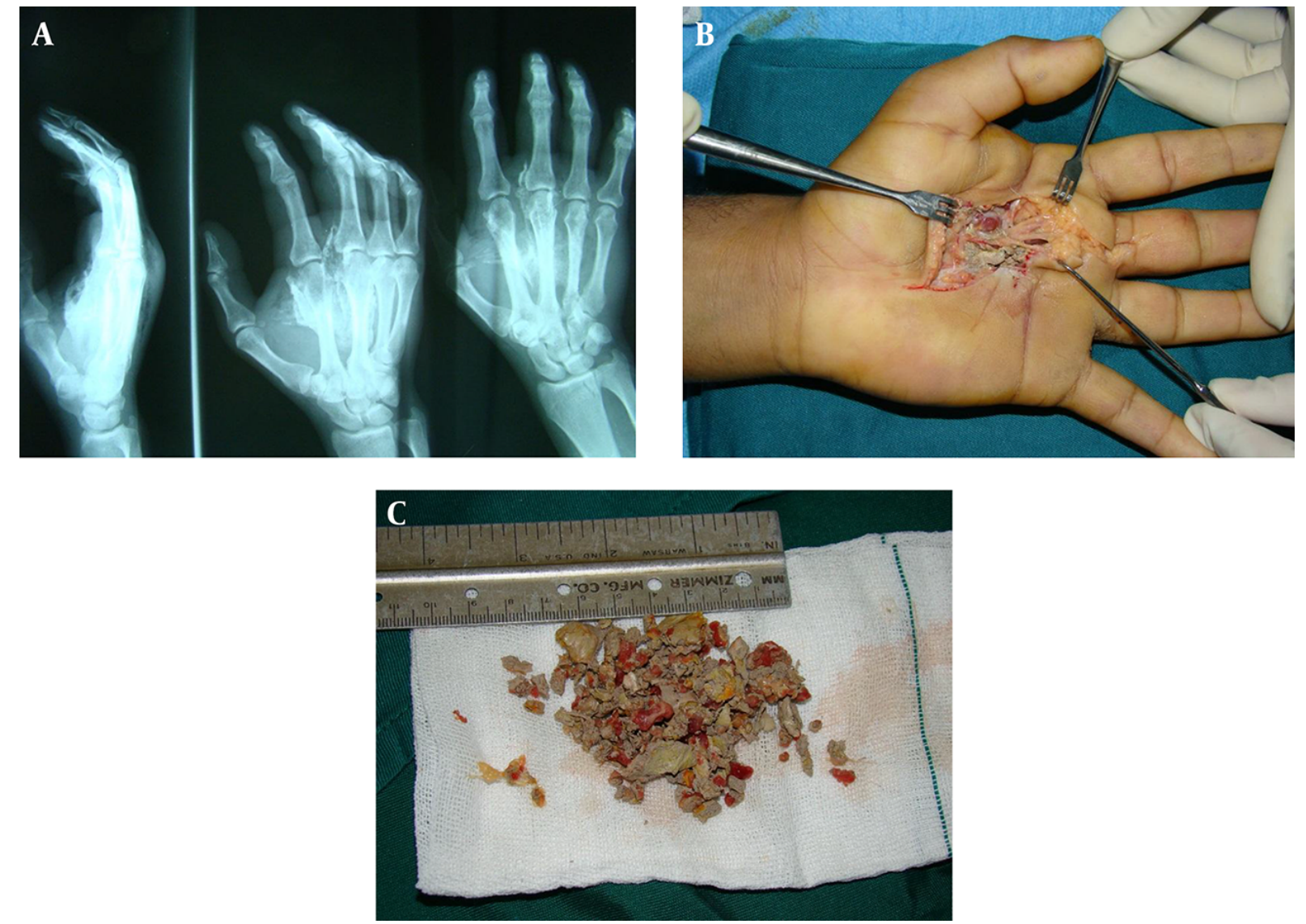

Figure 2. A, plain radiograph was used to estimate the extent of the injected materials (Case No. 6); B, intra operative findings allowed the most accurate assessment of the extent of the injury. (Case No. 6); C, meticulous debridement of all injected materials (Case No. 6).

Table 1. Demographic Data of Patients with High-Pressure Injury of the Hand

\begin{tabular}{|c|c|c|c|c|c|c|c|}
\hline No. & Gender & Age.y & Job & Dominancy & Inj. side & Involved Area & Injected Material \\
\hline $\mathbf{1}$ & M & 20 & Mechanic & RHD & Rt & Index volar & Grease \\
\hline 2 & M & 28 & Mechanic & RHD & Lt & Index volar & Grease \\
\hline 3 & M & 24 & Mechanic & RHD & Lt & Thumb volar & Grease \\
\hline 4 & M & 31 & Mechanic & LHD & Rt & Index volar & Grease \\
\hline 5 & M & 18 & Carwash worker & RHD & Lt & Palm thenar & Water \\
\hline 6 & M & 43 & Painter & RHD & Lt & Palm & Water base paint \\
\hline 7 & M & 28 & Mechanic & RHD & Lt & Thumb volar & Grease \\
\hline 8 & M & 21 & Painter & RHD & Lt & Index volar & Grease \\
\hline 9 & M & 29 & Mechanic & LHD & Lt & Index volar & Grease \\
\hline
\end{tabular}

Abbreviations: LHD, Left Hand; Lt, Left; RHD, Right Hand; Rt, Right; Male, M.

\section{Discussion}

High-pressure injury to the hand is caused by accidental injection of wide varieties of materials. These fluids are injected with high pressure ranging from 40 to $800 \mathrm{~atm}$ with a velocity as much as $180 \mathrm{~m} /$ seconds (4). The highly pressurized fluid can penetrate the skin through protec- 
Table 2. Management and Results of Patients with High-Pressure Injury of the Hand

\begin{tabular}{|c|c|c|c|c|c|c|c|}
\hline No & $\begin{array}{c}\text { Time to First } \\
\text { Treatment }\end{array}$ & Type of Treatment & $\begin{array}{c}\text { Times of } \\
\text { Operation }\end{array}$ & $\begin{array}{c}\text { Hospitalization } \\
\text { Time }\end{array}$ & $\begin{array}{l}\text { Outcome TAROM } \\
\text { Deficit, Degrees }\end{array}$ & $\begin{array}{c}\text { Back to Previous } \\
\text { Job }\end{array}$ & Follow up, m \\
\hline $\mathbf{1}$ & $24, \mathrm{~h}$ & $\begin{array}{l}\text { Debridement Cross } \\
\text { finger flap }\end{array}$ & 5 & 10 & 10 & $\mathrm{Y}$ & 26 \\
\hline 2 & $10, \mathrm{~h}$ & Debridement & 3 & 9 & 20 & $\mathrm{Y}$ & 18 \\
\hline 3 & $48, \mathrm{~h}$ & $\begin{array}{l}\text { Debridement Skin } \\
\text { graft }\end{array}$ & 4 & 7 & 15 & $\mathrm{Y}$ & 33 \\
\hline 4 & $72, \mathrm{~h}$ & $\begin{array}{l}\text { Debridement Skin } \\
\text { graft }\end{array}$ & 6 & 13 & 15 & $\mathrm{Y}$ & 48 \\
\hline 5 & $12, \mathrm{~m}$ & Nerve graft & 1 & 3 & 0 & $\mathrm{Y}$ & 25 \\
\hline 6 & $8, \mathrm{~h}$ & Debridement & 3 & 8 & $\begin{array}{l}170 \text { (mean deficit of } \\
\text { II to IV fingers) }\end{array}$ & $\mathrm{N}$ & 18 \\
\hline 7 & $13, \mathrm{~h}$ & $\begin{array}{l}\text { Debridement Skin } \\
\text { graft }\end{array}$ & 4 & 9 & 30 & $\mathrm{Y}$ & 36 \\
\hline 8 & $42, \mathrm{~h}$ & $\begin{array}{l}\text { Debridement Cross } \\
\text { finger flap }\end{array}$ & 5 & 13 & 40 & $\mathrm{Y}$ & 43 \\
\hline 9 & $7, d$ & $\begin{array}{l}\text { Amputation of the } \\
\text { necrotic digit }\end{array}$ & 1 & 3 & - & $\mathrm{N}$ & 10 \\
\hline
\end{tabular}

Abbreviations: N, no; Y, yes; TAROM, total active range of motion.

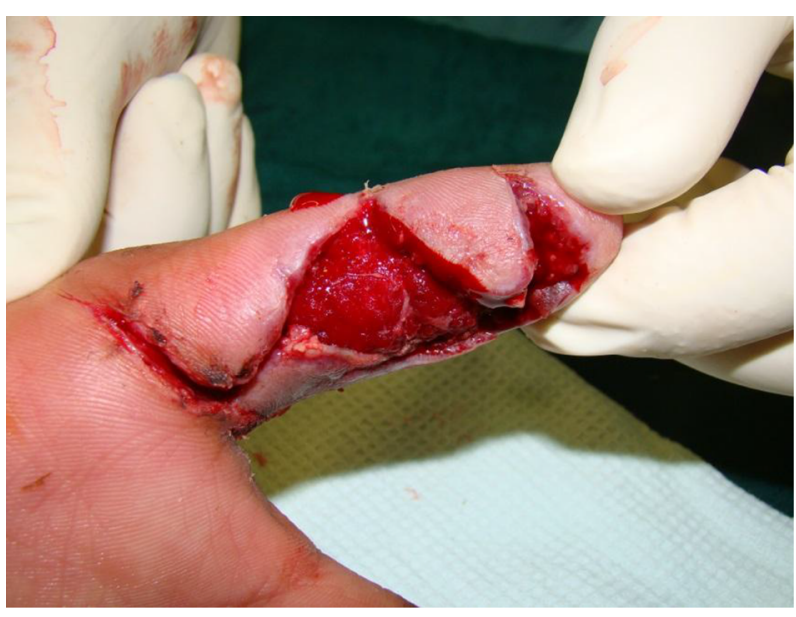

Figure 3. Multiple Debridement Done Until an Infection-Free and Highly-Vascular Bed Was Achieved (Case No. 3)

tive gloves without direct contact with the hand (5).

Various types of industrial equipment and substances including paint, paint thinner, gasoline, oil, grease and even water, have been reported (a,b). Grease, diesel and paint are the most commonly reported injected substances. This was the same as the results of our study, in which grease was the most common injected material (1, 2).

Several mechanisms have been reported in the pathophysiology of vast soft tissue injury. The kinetic energy of the injected material can result in immediate soft tissue necrosis. Edema, vascular spasm, chemical irritation, necrotizing inflammatory reaction due to cytolytic properties of these materials and finally infection are the involved factors in developing severe damage to the vital and delicate soft tissue of the hand (2).

The non-dominant hand and index finger are at a higher risk to be injured $(2,6,7)$. This was true with our patients, where the index finger of the non-dominant hand was involved most of the time.

Prognosis of the injury is under influence of multiple factors. Nature of the injected material is the most important item. Paint and chemical solvents are more irritating than water, and water based materials or greases. The injection pressure is the prognostic factor. Higher pressure results in more intense and severe damage and necrosis $(6$, 7). Volume of the injected material and also the site of injection are important in dictating the prognosis. Finally time delay of the incident and the treatment is a determinant factor $(6,7)$.

After high-pressure injection, the presenting sign and symptoms are usually minimal. Pain and swelling at the initial presentation are not significant. The entrance of the foreign materials is a small pinprick and this can lead both the patient and heath care personnel to underestimating the injury, which in turn results in a delay in the initiation of the classic treatment and urgent decompression. Eventually, the injured part becomes swollen and painful. In a few hours it will edematous, pale, cold and the chance for 

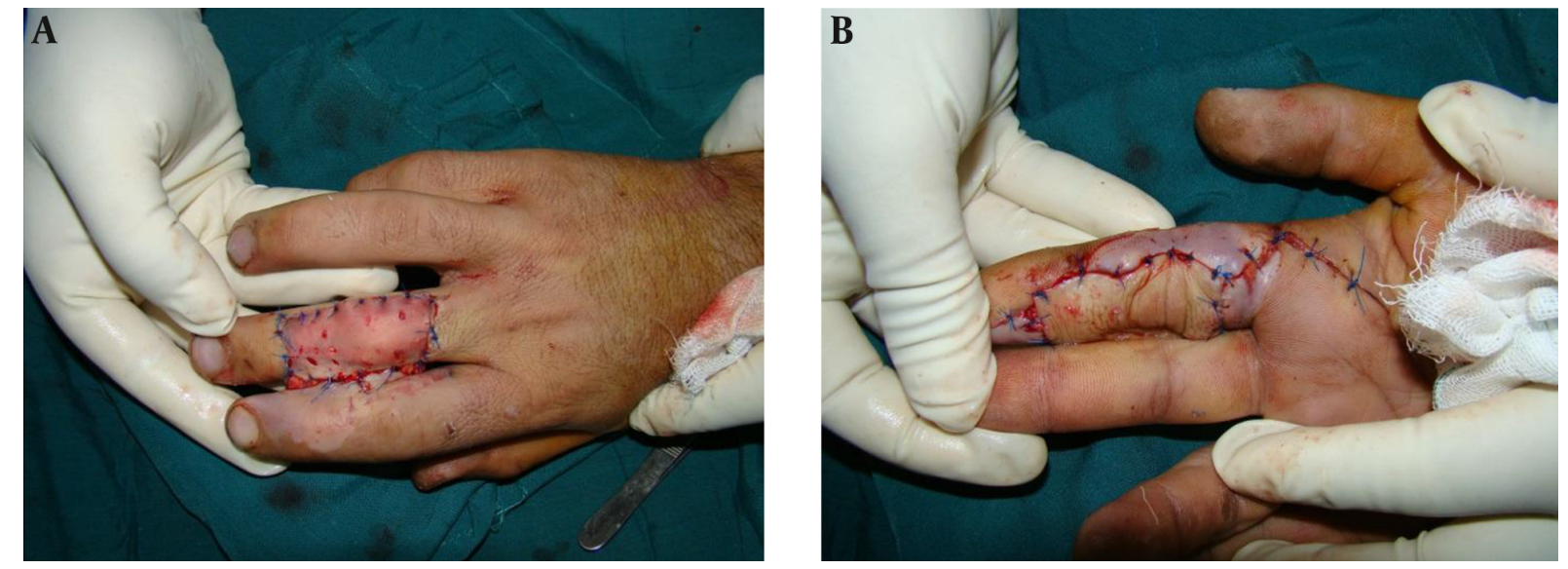

Figure 4. A and B Cross Finger Flap to Reconstruct the Volar Injured Area (Case No. 1)

irreversible damage and amputation will increase.

The amputation risk is about $16-55 \%$. It will be as high as $50-80 \%$ when the injected material is a solvent (8). Time delay of treatment initiation is also a prognostic factor for amputation risk. Stark et al. reported that, treatment during the first 10 hours after injury results in better outcome (9). Another study reported that they did amputation for patients, who were admitted after a 72-hour delay (7).

Mean time delay to first treatment procedure for our patients was $29.16 \pm 25.66$ hours for seven patients and none of them had amputation. The only case of amputation was for case No. 8, who had referred to our center after seven days of delay without any treatment for the injection injury. This low rate of amputation in our patients may be partly due to the nature of the injected materials, which were grease most of the time. The other possible factor is the initiation of primary urgent surgical decompression and debridement as soon as possible after admission to the hand surgery department.

Treatment of the injury needs a classic approach. The patient should be admitted to the hospital and broadspectrum antibiotics should be administered. The role of the corticosteroids in prevention of amputation was a challenge in the recent years and there is no consensus on its efficacy (1). Immediate surgical decompression of the injected site (usually a digit) should be done. All injected foreign and devital necrotic tissues should be removed with delicate dissection. The wound should be irrigated with enormous amount of normal saline without using a chemical solvent. The wound should be left open for a second look, which should be 48 - 72 hours later. This sequence of procedures should be done until a highly vascular and infection-free bed is available for the final operation. The nature and extent of the injury as well as the outcome of the multiple irrigation and debridement dictate the kind of the final procedure, which can be a simple skin graft or a more challenging reconstructive procedure $(4,5)$. This algorithmic approach was used for all of our patients.

The outcome after a high-pressure injection injury is reportedly disappointing. Amputation rate is high and the injury burdens devastating sequels, which downgrade the function of the hand (3). According to the literature, a small percentage of injured patients can resume their original work and duties (10). In our series two out of nine patients were able to continue their previous job. This indicates the devastating nature of this kind of injuries.

There are several shortcomings for our study. The size of the series is small and also the follow up period is not long-term. Thus future studies should recruit patients by running a multiple center study and follow the patients in the long-term.

This study emphasizes the findings of previous studies that urge clinicians to not underestimate these benign looking injuries and perform immediate surgical decompression alongside other classic recommendations.

\section{Footnote}

Authors' Contribution: Study concept and design: Davod Jafari; drafting of the manuscript and critical revision of the manuscript for important intellectual content: Davod Jafari, Tahmineh Mokhtari, Hooman Shariatzadeh and Toraj Kamali; statistical analysis: Tahmineh Mokhtari; Study Supervision: Davod Jafari. 


\section{References}

1. Hogan CJ, Ruland RT. High-pressure injection injuries to the upper extremity: a review of the literature.J Orthop Trauma. 2006;20(7):503-11. [PubMed: 16891944].

2. Failla JM, Linden MD. The acute pathologic changes of paint-injection injury and correlation to surgical treatment: a report of two cases. J Hand Surg Am. 1997;22(1):156-9. doi: 10.1016/S0363-5023(05)80197-2. [PubMed: 9018630].

3. Pinto MR, Turkula-Pinto LD, Cooney WP, Wood MB, Dobyns JH. Highpressure injection injuries of the hand: review of 25 patients managed by open wound technique.J Hand Surg Am. 1993;18(1):125-30. doi: 10.1016/0363-5023(93)90256-3. [PubMed: 8423296].

4. Neal NC, Burke FD. High-pressure injection injuries. Injury. 1991;22(6):467-70. [PubMed: 1757138].

5. Rosenwasser MP, Wei DH. High-pressure injection injuries to the hand. J Am Acad Orthop Surg. 2014;22(1):38-45. doi: 10.5435/JAAOS-22-
01-38. [PubMed: 24382878].

6. Christodoulou L, Melikyan EY, Woodbridge S, Burke FD. Functional outcome of high-pressure injection injuries of the hand. J Trauma 2001;50(4):717-20. [PubMed: 11303170].

7. Valentino M, Rapisarda V, Fenga C. Hand injuries due to high-pressure injection devices for painting in shipyards: circumstances, management, and outcome in twelve patients. Am J Ind Med. 2003;43(5):53942. doi: 10.1002/ajim.10218. [PubMed: 12704627].

8. Schnall SB, Mirzayan R. High-pressure injection injuries to the hand. Hand Clin. 1999;15(2):245-8. [PubMed:10361635].

9. Stark HH, Ashworth CR, Boyes JH. Paint-gun injuries of the hand.JBone Joint Surg Am. 1967;49(4):637-47. [PubMed: 5338035].

10. Wieder A, Lapid O, Plakht Y, Sagi A. Long-term follow-up of high-pressure injection injuries to the hand. Plast Reconstr Surg. 2006;117(1):186-9. [PubMed: 16404265] 